\title{
Tuberculosis: Basic and Clinical Relevant Aspects
}

\author{
Alejandro Schcolnik-Cabrera' ${ }^{1}$, Patricia Orduna ${ }^{2}$, Samuel Ponce de Leon ${ }^{2}$ and Yolanda Lopez-Vidal1* \\ ${ }^{1}$ Department of Microbiology and Parasitology, National Autonomous University of Mexico, Mexico \\ ${ }^{2}$ Department of Microbioma, National Autonomous University of Mexico, Mexico
}

Submission: February 06, 2017; Published: March 23, 2017

*Corresponding author: Yolanda Lopez-Vidal, Department of Microbiology and Parasitology, National Autonomous University of Mexico, Mexico, Tel: +52-(55)-5616-0844; Fax: +52-(55)-5616-0844; Email: lvidal@unam.mx

Abstract

Tuberculosis remains a major public health problem around the world. This disease is caused by M. tuberculosis. The World Health Organization (WHO) estimated 10.4 million new tuberculosis cases worldwide in 2015 and 1.4 million of deaths in the same period. Besides, an estimated of 2 billion people worldwide have latent tuberculosis infection, from which $10 \%$ will develop tuberculosis disease.

The emergence of antibiotic-resistant strains associated to more aggressive clinical entities is a challenge in tuberculosis treatment. It is estimated that, in 2010, about 650,000 tuberculosis cases were resistant to isoniazid and rifampicin. This situation forces governments to maintain a permanent surveillance of the sensitivity in new bacterial isolations.

In this review we discuss tuberculosis generalities, from the general description of the pathogen and its epidemiological effect to clinical entities, diagnosis, and treatment associated with the infection.

Keywords: Tuberculosis; Pathogenesis; Clinical manifestations; Diagnosis; Treatment

Abbreviations: AAFB: Acid Alcohol Fast Bacilli; AIDS: Acquired Immune Deficiency Syndrome; BCG: Bacillus Calmette-Guérin; CDC: Centre for Disease Control; CNS: Central Nervous System; Cyd: Cytochrome bd oxidase; DNA: Deoxy Ribonucleic Acid; ELISA: Enzyme-Linked Immunosorbent Assay; GM-CSF: Macrophage Colony Stimulating Factor; HIV: Human Immunodeficiency Virus; LAM: Lipoarabinomannan; MDR: Multidrug Resistant Strain; PCR: Polymerase Chain Reaction; PET-CT: Positon-Emission Tomography with Computed Tomography; PPD: Purified Protein Derivate; rBCG: Recombinant BCG Strains; TLR: Toll-Like Receptors; WHO: World Health Organization; XDR: Extensively Resistant Strain

\section{Epidemiology}

Tuberculosis is a global problem of public health. Only in 2015, the World Health Organization (WHO) estimated 10.4 million new incident cases worldwide (Figure 1), mostly in India, China, Nigeria, Pakistan, and South Africa and 1.4 million tuberculosisassociated deaths during the same year [1]. Additionally, there were an estimated 100 cases per 100,000 habitants/year of tuberculosis incidence worldwide [2]. Among the tuberculosisrelated deaths, more than $95 \%$ occur in low and medium income countries, being tuberculosis the principal cause related with patients infected with the human immunodeficiency virus (HIV) [3]. In fact, the WHO reported that almost 1.2 million incident tuberculosis TB cases subjects were co-infected with HIV by 2015 [1]. Furthermore, it is estimated that 2 billion people worldwide are latently infected by the tuberculosis bacterium $[4,5]$. Among them, nearly $10 \%$ will develop some presentation of the disease [6].

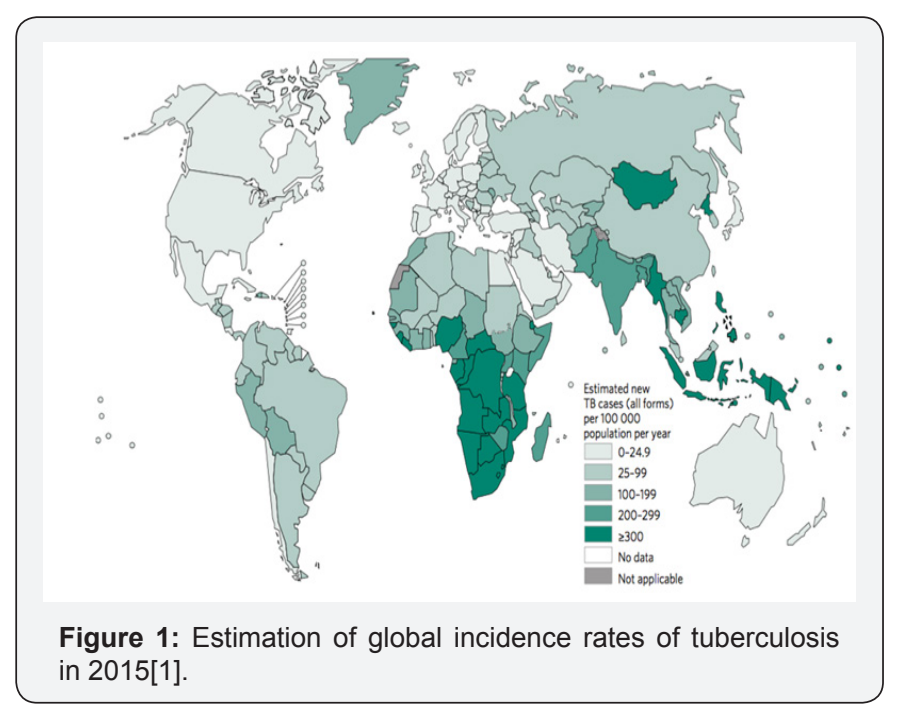


Tuberculosis is an old disease, which pathogen has evolved together with the human [7]. This was evident in a Turkish study that identified a 500,000-year old Homo erectus fossil with typical lesions of tuberculosis [8]. However, it has been estimated the existence of an early progenitor of Mycobacterium tuberculosis 3 million years ago in East Africa, and it is possible that all members of the Mycobacterium tuberculosis complex share a common African ancestor 35,000-15,000 years ago [9]. Despite its antique, the first's descriptions of this disease were done by Hippocrates, Paracelsus and Galen and then, in the classical Greece, the tuberculosis was a well-recognized pathology under name of phthisis [9]. To 1882, Robert Koch identified Bacterium tuberculosis as causal agent of tuberculosis [10]. After that in 1896, Lehmann and Neumann named it Mycobacterium tuberculosis [11].

Among the M. tuberculosis strains that infect the human, there are two "antique strains" that remain in Africa, while the remaining strains are spread in the rest of the world [8]. Recently, new $M$. tuberculosis strains have emerged, which are resistant to the election antibiotics and they are associated with a more aggressive clinical presentation. In 2010, it is estimated that approximately 650,000 tuberculosis cases were resistant to the first-line drugs (isoniazid and rifampicin) [12].

The WHO plans to significantly reduce both the incidence and death associated with tuberculosis between the years 2015 and 2030 [13]. To achieve this goal, several strategies have been designed; they include development of: new vaccines, quick diagnostic tests, and better treatments schemes [8,11]. Regardless the knowledge of the risk factors related to tuberculosis and its evolution to the active disease (including poverty, overcrowding, malnutrition, alcoholism, HIV infection, silicosis, chronic kidney failure, diabetes, smoking, and immunosuppressive therapy [6]), we still lack information on how this predisposition factors interact to activate the disease in each patient [14].

\section{Etiological Agent}

Tuberculosis is caused by a group of phylo genetically related bacteria known as Mycobacterium tuberculosis complex [15]. This complex includes M. tuberculosis, M. bovis, M. bovis (BCG), M. africanum, M. microti, and M. canettii, which share more than $99 \%$ of identity at nucleotide level [16]. In humans, the tuberculosis disease is usually caused by M.tuberculosis and M. africanumstrains, bothobligate human pathogens without known animal reservoir [17] and with limited survival time outside the host [16]. Besides, the M. bovis strain has been related to human infections, particularly in a zoonotic way with unpasteurized milk as a source [1].

M. tuberculosisis an intracellular bacterium that lives and duplicates inside the phagosome of macrophages, this bacteria may also initially infect type II pneumocytes in the pulmonary alveoli [18].

The Mycobacterium bacillus is slightly curved, with a size close to $1-4 \mu \mathrm{m}$ in its major axis and $0.3-0.6 \mu \mathrm{m}$ in its minor axis, while its replication time is $12-24$ hours [19]. It is poorly Gram (+ve), aerobic, immotile, and of slow growing; it is not a sporeforming bacterium and is characterized by a cellular wall that is rich in $\alpha$-acetylated and $\beta$-hydroxylated long-chain fatty acids, mostly mycolic acids $[17,20,21]$ (Figure 2).

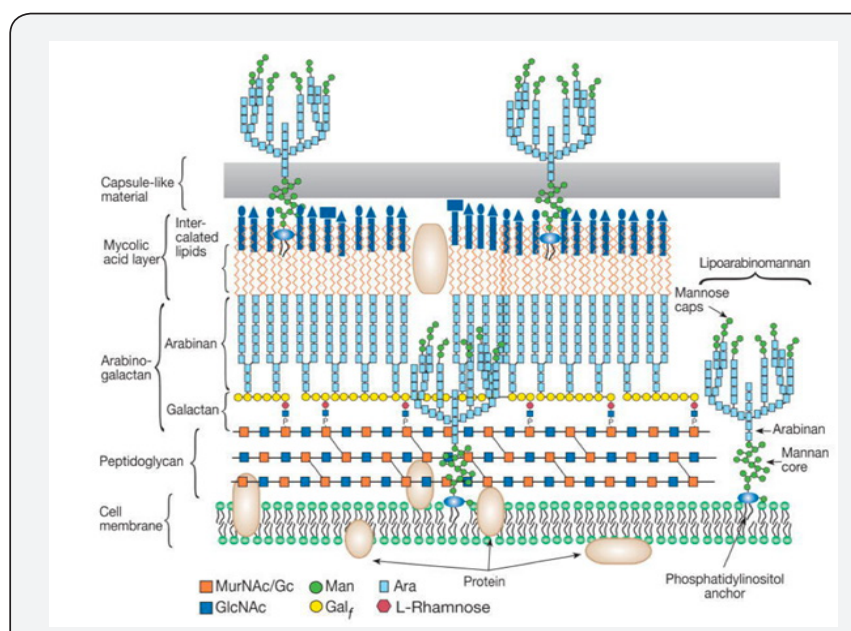

Figure 2: Structure of the cellular wall of Mycobacterium [132].

Among other functions, the cellular wall confers to mycobacteria resistance to antibiotics, acid and alkaline environments, and intrinsic resistance to desiccation. The cellular wall composition also confers an extreme hydro phobicity to the bacilli [19]. The staining use in mycobacteria identification is the Ziehl-Neelsen staining [22]. This technique is based in the usage of carbol-fuchsin dye, with a posterior wash with acid alcohol and ending with methylene blue dye [23]. However, since $M$. tuberculosis has a high concentration of fatty acids in its cellular wall, acid alcohol is insufficient to completely remove the carbolfuchsin; therefore, the bacteria are visualized as red-pink with a contrasting blue background. Then, M. tuberculosis is known as an acid alcohol fast bacilli (AAFB) [24].

The genome of M. tuberculosis has a high guano sine and cytosine concentrations [20] with around 65.5\%. From the approximate 4,000 genes in its genome, more than 200 are destined to fatty acid metabolism [18]. This could be related with the growth capacity in the tissues of the host, where fatty acids may represent the main carbon source for the bacteria [18].

\section{Pathogenesis}

Tuberculosis bacilli are usually acquired by the inhalation of droplets, which are expelled by sick subjects [25], but also by ingesting contaminated non-pasteurized milk [11] and by direct inoculation [2]. Among the droplets that come with cough, the biggest fall to the ground and those of $1-5 \mu \mathrm{m}$ diameter [26], which can be considered small, remain suspended in the air and can evade filtering processes in the upper respiratory airway to be quickly deposited in the pulmonary alveoli [14]. These secretions, known as "Flügge droplets", contain the tuberculosis bacillus. Flügge droplets have been associated with the transmission of the disease from a previously infected patient 
that coughs, speaks and sneezes close to a healthy subject, because of the high probability of inhalation and deposit of such droplets into the alveoli $[27,28]$.

Wells and Riley expanded this concept through an equation (Wells-Riley equation). They evaluated the risk of transmission based on the amount of Flügge droplets required to infect, which they called "quanta", inside a defined space [27]. Furthermore, Wells demonstrated that after the evaporation of the fluid of such droplets, the nuclei can still mobilize in an aerodynamic fashion for their quick dispersion in the environment [28].

The development of the disease results from the evolutionary strategy of $M$. tuberculosis [6]. The initial innate immune response progresses to an adaptive form due to the immunological activation, which tries to control the infection. Only the equilibrium of the effector mechanisms of the cytokines regulates the response and determines whether the host is susceptible or resistant to infection by M. tuberculosis [29]. Although the initial immune recognition could be generated by dendritic cells or even neutrophils [14], the first human cell that encounters the bacterium is the alveolar macrophage, which phagocytes it but does not destroy it since this process is inhibited by the pathogen itself [8].

It is suggested that the endosome containing the bacterium does not maturate because M. tuberculosis interrupts its acidification by the release of ammonia [30] given that the mycobacteria prefer to grow in a neutral $\mathrm{pH}$ [31]. Additionally, the phagosome-lysosome fusion event is stopped by mycobacteria, which inhibited the $\mathrm{Ca}^{2+}$ sensor synaptotagmin (Syt-7). Finally, diverse phenolic glycolipids of the cellular wall of M. tuberculosis prevent the production of pro-inflammatory cytokines in macrophages [32].

There is a potent $\mathrm{Th}_{1}$-mediated immunity in macrophages that produce nitric oxygen to try to kill the bacilli by competing with the oxygen at the binding site on the cytochrome c-oxidase in the cellular respiration chain of the mycobacteria. Regardless, Mycobacterium is capable to arrest its replication down regulating its respiratory pathway. Then, it avoids the collapse of the electron flow by the parallel up-regulation of a less efficient Cytochrome bd Oxidase (Cyd) and of the Nitrate Transporter Nar K. They can restore the redox balance by working as an antioxidant (Cyd) and a machinery to reduce nitrates (Nar K) inside the bacteria cell, reducing ATP synthesis in the pathogen [33].

Therefore, Mycobacterium has two progressive metabolic states according to the increase in the pressure by hypoxia: one of non-replicating persistence with oxygen levels reduced to $1 \%$ saturation and the other of a complete shutdown of metabolism when oxygen is consumed at less than $0.06 \%$ saturation [34]. Thus, the bacterium can safely live inside the macrophage under both aerobic and anaerobic conditions, where it is capable of replicating every 25 hours [35].
Apoptotic macrophages have an important role in adaptive immunity because the dendritic cells acquire exogenous antigens from apoptotic vesicles of infected macrophages [36]. The dendritic cells transport $M$. tuberculosis to the lymphatic system, migrating to the regional lymph nodes where they present the mycobacteria antigens to T-lymphocytes [14].

The previously referred response in which macrophages experience apoptosis in order to present antigens to dendritic cells is evident in M. tuberculosis strains with low virulence power. Indeed, it has been reported that macrophages infected with the non-virulent strain H37Ra produce prostanoids, including $\mathrm{PGE}_{2}$, that generate apoptosis and a $\mathrm{Th}_{1}$ immune response. However, if the macrophages are infected with the virulent strain $\mathrm{H} 37 \mathrm{Rv}$, they preferentially synthesize lipoxin $\mathrm{A}_{4}$, a negative regulator of the acute inflammatory response, that promotes necrosis in macrophages instead of apoptosis [37]. Highly virulent $M$. tuberculosis strains stimulate necrosis by mitochondrial transition of permeability, which allows the release of cytochrome $\mathrm{C}$ and the further activation of the caspase pathway [38]. Together, these changes generate accelerated cell death with plasmatic disintegration that protects the mycobacteria [37]. On the other hand, virulent strains of $M$. tuberculosis in pre-necrotic macrophages continue duplicating and are propagated when the cell is lysed [39].

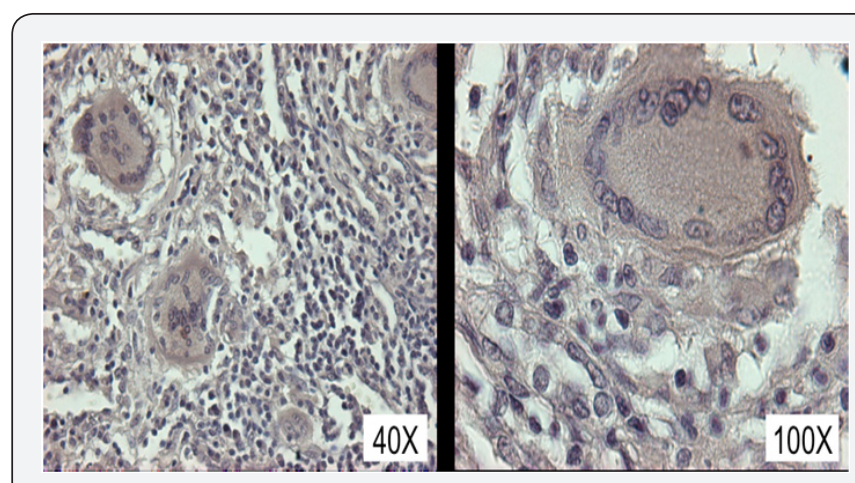

Figure 3: Granuloma in tuberculosis Photomicrography of lung tissue with presence of a granuloma showing giant multinucleated cells (H\&E, 40x and 100X).

A competent immune response is evident when the alveolar macrophage and the dendritic cell present the microbial antigen to $\mathrm{CD}^{+}{ }^{+}$T-lymphocytes. Both IL- 6 and IL-12 are then required to generate and expand $\mathrm{Th} \mathrm{C}_{1} \mathrm{CD} 4$ clones for the production of cytokines, as INF- $\gamma$, that stimulate the differentiation of circulating monocytes to macrophages. In turn, the macrophages phagocyte the bacilli [40-42] and promote the production of nitric oxide syntheses 2 to control bacterial growth [43]. Furthermore, the stimulation of $\mathrm{Th}_{1}$ immune response is associated with the formation of granulomas at the infection site for the encapsulation of the bacteria inside of the macrophage (Figure 3). The granuloma is composed by a central nucleus of caseous necrosis, surrounded by neutrophils, dendritic cells, natural killer cells, epithelioid cells (macrophages that have 
undergo a maturation process), macrophages originated from circulating monocytes, and multinucleated gigantic cells known as "Langhans giant cells" that derive from epithelioid cells, delimited by T- and B-lymphocytes, and fibrosis [44].

The specific recruitment of macrophages to the site of infection is related with TNF- $\alpha$ secreted by infected T-lymphocytes and macrophages, which secures high levels of the chemokines CCL2/MCP-1, CCL12 and CCL13, all of which bind to the CCR2 receptor for the enrolment of macrophages [45]. Certainly, TNF- $\alpha$ is recognized as the orchestrator of granuloma formation and maintenance since its presence is mandatory for the correct traffic of macrophages, and because mice deficient in TNF- $\alpha$ lack the ability to form organized granulomas [46].

Although the granuloma was previously regarded as a protective strategy of the host, now they are recognized to have a role as the niche for M. tuberculosis replication [6]. Particularly in the case of mycobacteria expressing the ESX-1 secretion system encoded by the RD1 locus, also recognized as highly virulent bacteria, it has been suggested that granuloma might support bacilli proliferation since RD1-deficient bacteria induce arriving macrophages to the infection site with slower movement and without morphological characteristics similar to those presented by leukocytes undergoing chemo taxis, which are features of motile macrophages that cover more area for phagocytosis [46]. Consequently, RD1-mediated chemo tactic motility of macrophages is exploited as an advantage by $M$. tuberculosis, since infiltrating macrophages phagocytose the contents of dying cells and therefore the number of infected cells can increase [46].

This statement is supported by the fact that RD1-mutant bacilli induce slower kinetics of macrophage recruitment and function, which is related with inhibition in bacterial proliferation [46]. On the other hand, the mycobacteria that survive the immune response latently stay in the granuloma for decades and generate tuberculosis infection, asymptomatic and non-transmissible [11], with the potential of reactivation [29]. The patients with latent infection are considered as noninfective, despite having a $10 \%$ risk of showing reactivation through their life time [47].

There must be a balance of both pro-inflammatory and anti-inflammatory responses to limit mycobacterial proliferation within the granuloma, and a dysregulation leads to reactivation and disease. With the reactivation, there is a localized inflammatory response of high magnitude: the center of the granuloma curses with necrosis and then undergoes liquefaction, which provides a rich source of pathogenic elements [6]. In fact, it has been identified that once the central necrosis process has started, macrophage-differentiated foam cells, which are characterized by high lipid accumulation, appear flanking the necrotic site to accumulate caseous residues and function as hosts for the nutrition of mycobacteria by the supply of lipid bodies [48]. A virulent bacillus that is released from the granuloma then can migrate to other sections of the lungs to induce more lesions, and if the granuloma breaks into the airway, the mycobacteria is able to be transmitted to other subjects [45].

\section{Clinical Presentations}

Most of the infected patients with $M$. tuberculosis are asymptomatic [6]. M. tuberculosis has the potential of infecting every organ in the body, and pulmonary tuberculosis is the most frequent infectious presentation because of the cavitations that harbor a high number of bacteria with the potential of spreading with coughing. In contrast, the extra pulmonary presentation of tuberculosis may be contagious [8], depending on its localization. It is considered that the patient has primary tuberculosis if he develops the disease as a response to the initial exposition to the bacilli; while, secondary tuberculosis relies on a reactivation [49]. However, the Center for Disease Control (CDC) of the United States describes the presentations as follows: latent infection, tuberculous disease, and extra pulmonary tuberculosis. In this section we will address each of them.

\section{Latent tuberculosis}

It is estimated that close to 2 billion people around the world are latently infected with tuberculosis bacilli [50]. After the inhalation of M. tuberculosis, the immune system of the host restricts the permanence of the bacilli without replication or with a low rate of replication inside the alveolar macrophage. This explains the asymptomatic clinical curse of patients who are non-infectious after typically normal thoracic radiographs, negative microbial culture, sputum tests, and an absence of tuberculosis disease [26]. This presentation is detectable by the tuberculin cutaneous test or by the IFN- $\gamma$ release assay, but 2-8 weeks after the infection are required to allow the immune system to react against tuberculin and detect the infection [26]. The viable bacilli can persist in the necrotic material of the granuloma through several years; however, under an immune suppression state as the co-infection with the HIV virus, the presentation advances to active disease [51].

\section{Tuberculous disease}

This kind of tuberculosis occurs when the bacilli evade the immune system and multiply enough to progress from the latent disease [26]. The tuberculous disease is related with several conditions, including poverty, alcoholism, immune suppression, and advanced age [52]. It is estimated that without treatment, around $5 \%$ of the patients evolve within the firsts two years after the infection to the tuberculous disease and 5\% develop it at some point of their lifetime [26].

The most common presentation is the pulmonary tuberculosis, and unlike the latent form, tuberculous disease is contagious. Obtaining a diagnosis is possible after radiological tests, and/or with the identification of bacteria in either sputum or culture and recognizing bacterial colonies in agarose [26]. The patient commonly curses with productive cough, mucopurulent 
sputum, weight loss, progressive adynamia, anorexia, fever, nocturnal diaphoresis, general discomfort and sometimes hemoptysis of variable volume [52].

The disease is insidious at the beginning, with initial nonproductive cough that turns productive with purulent sputum and hemoptysis, associated with pulmonary tissue destruction by cavitations and pleuritic pain secondary to the inflammation in the pulmonary parenchyma [51]. Additionally, patients can develop paratracheal lymphadenopathy because of the dispersion of the bacteria from the lungs to the lymphatic system. They curse with pleural effusion if the bacilli infiltrate the pleural space because of the rise in the size of the primary lesion [51]. If the size of the effusion is small, then it may be spontaneously solved or increase its size together with fever, pleuritic pain, and dyspnea [51].

With the progression of the disease, the clinical manifestations increase in intensity. Emaciation commonly occurs secondary to anorexia and metabolic alteration by inflammation [51]. Acropachy is a late sign of poor oxygenation and is present in chronic patients [51]. The extended disease generates dyspnea or orthopnea because the pulmonary diffusion capacity is diminished with the increase of the interstitial volume [51].

The study of the sputum, the culture in liquid mediumor in agar in low-income countries because of the low costs, susceptibility to antibiotics, and recently, the use of rapid tests as Interferon-Gamma Release Assays (IGRAs), are recommended as standard methods for the diagnosis of tuberculoses disease [53]. Besides, it is recommended to run tests in at least two specimens of morning sputum in order to search for the bacilli when the patients show persistent cough for three or more weeks without response to treatment, particularly if they live in underdeveloped countries from Africa, Asia, and Europe [52]. Hematic biometry studies can demonstrate anemia, the cause of asthenia and adynamia, and leukocytosis in response to the infection [51].

Furthermore, in recent years a clear correlation between the reactivation of previously dormant tuberculosis bacilli and immunosuppressive therapies against autoimmune diseases has been identified. The first example comes with lupus, in which patients undergoing high cumulative dose of steroid or other immunosuppressive therapy are most susceptible to tuberculous infection by M. tuberculosis. In this case, it is common to find extra pulmonary involvement and dissemination through the body by the modulation of IFN- $\gamma$ production and the proliferation of cells reacting to mycobacterial antigens [54]. A delayed diagnosis is common since extra pulmonary tuberculosis can mimic inflammatory arthritis, systemic lupus erythematosus pleurisy, and even cellulitis [55]

On the other hand, it is widely known that the reactivation of latently infected subjects with the tuberculosis bacilli is possible if the patients are treated with biological agents like TNF- $\alpha$ antagonists, as the chimeric monoclonal antibody Infliximab, since the firsts months of treatment [56,57]. This drug is part of the treatment scheme given to rheumatoid arthritis patients to diminish pathologic inflammatory events. As with lupus, rheumatoid patients are more susceptible to develop extra pulmonary presentation of tuberculosis. Indeed, some studies have estimated the relative risk of reactivation of tuberculosis driven by Infliximab increases up to 25 times [58]. This effect can be explained by the pharmaco dynamic effect of Infliximab on the formation of complexes with both the monomeric and trimeric forms of soluble and trans membrane TNF and in consequence, on the inhibition of the phagocytosis of mycobacteria by macrophages [59]. Together with a reduction in IFN- $\gamma$ levels by immune modulators, the process of mycobacteria killing is compromised [60].

\section{Extra pulmonary tuberculosis}

This presentation occurs in sites other than lungs, and affects $10-43 \%$ of the infected patients, depending on the race, age, presence of a previous disease, $M$. tuberculosis strain genotype, and immunological state [51]. The probability of extra pulmonary tuberculosis is augmented in immune suppressed subjects, particularly in those infected by HIV. In this situation, patients may present both tuberculous disease and extra pulmonary tuberculosis [26]. Extra pulmonary tuberculosis patients are recognized as highly contagious as in the case of subjects with presentations in the oral cavity or the larynx and those who possess open abscesses with the bacilli in high concentrations [26]. Otherwise, patients with extra pulmonary tuberculosis are not infective because the bacilli are contained inside the tissues.

In this section we will analyze the most lethal presentations of extra pulmonary tuberculosis, known as miliary tuberculosis, meningeal tuberculosis and tuberculous lymphadenitis.

\section{Miliary tuberculosis}

Disseminated tuberculosis or miliary tuberculosis is a severe form of extra pulmonary tuberculosis in the dispersed infection in blood. The word "miliary" alludes to the radiographic appearance of millet seeds widely distributed across the pulmonary field [26]. This condition is more common in children of under 5 years of age, alcoholic subjects, those with chronic renal failure or malnourished, and immune suppressed patients with HIV coinfection, diabetes, under treatment with corticosteroids, and/ or undergoing chemotherapy [26,61]. Its presentation depends on the massively phohematic dissemination from pulmonary or extra pulmonary focus and the embolization in vascular beds from different organs in the body [61].

Miliary tuberculosis has been related with an insufficient immune response by the host against $M$. tuberculosis. Since the innate and the adaptive immunity systems act coordinately in a synergic way, an incomplete control of the bacterium is identified in both and allows the proliferation of the bacterium 
and its systemic dissemination. In the innate immune system, the strong bind M. tuberculosis-macrophage has been identified. This process is mediated by mannose-binding lectins, surfactant protein $\mathrm{A}$, and the complement protein $\mathrm{C} 1 \mathrm{q}$, whose mutations are risk factors for the bacterium uptake and the posterior development of tuberculosis [62]. Additionally, if mutations in Toll-like receptors (TLR)-2 and/or 4 are present, the intracellular recognition of the bacilli would be compromised [62]. On the other hand, the adaptive immune system action is related with T-lymphocyte function, but the presence of HLA-Bw15 and HLADRB1*15/16 haplo types in the host is related with tolerance to the bacterium and the further presentation of the disease [63].

The miliary form of tuberculosis is multi organic, progresses quickly and can be difficult to diagnose because of its unspecific symptom atology, which includes chronic fever with mourning peaks, nocturnal diaphoresis, weight loss, anorexia, nonproductive cough, and asthenia $[51,63]$. Highly irrigated organs, as spleen, liver, bone marrow, kidneys, and adrenal glands, are frequently affected [61]. Besides, most of the patients with miliary tuberculosis also have pulmonary tuberculosis and around $25 \%$ of patients with miliary tuberculosis also have meningeal damage [26].

The pathognomonic sign of miliary tuberculosis is the presence of granulomas in the affected organs together with small grey/red uniformly round macular lesions [61]. The diagnosis of this presentation of tuberculosis requires the presence of miliary infiltrate by thoracic radiography or by computed tomography, although the diagnosis can also be done identifying miliary tubercles by laparoscopy or surgery in the involved organs [61]. However, reports have shown that miliary tuberculosis can be misdiagnosed as another infectious disease and only correctly diagnosed until necropsy [51].

\section{Meningeal tuberculosis}

Despite being commonly present with low bacterial counts, the most dangerous localization of tuberculosis is the central nervous system (CNS) [64]. Nearly 1\% of all clinical cases of tuberculosis affect the CNS, being malnourished children and patients infected with HIV the principal risk groups [65]. Around $30-40 \%$ of the affected patients die [66] and more than $50 \%$ of the survivors remain disabled [67]. The CNS infection with the bacilli causes tuberculomas in the brain surface, commonly referred to as Rich focus or meningitis [68]. They constitute the most important pathway for the introduction of the bacteria into the subarachnoid space [65]. This presentation occurs when the mycobacterium is hosted in the tissue surrounding either the brain or the spinal cord, with the concomitant immune response towards both the bacterium and its released antigens [26]. This immune reaction may block the cerebrospinal liquid flux in the host to generate hydrocephaly, ischemia, and infarcts, mostly in the anterior basal ganglia [68]. Indeed, it has been suggested that the metalloproteinase (MMP)-9, produced by microglial cells to control the infection, could in fact degrade the extracellular matrix of the brain [67]. The symptom atology-headache, altered mental status that progresses to coma, neurological signs including monoplegia or paraplegia, and cervical rigidity after exposition to tuberculosis or in high risk groups-indicates the necessity to consider this disease in the differential diagnosis $[26,51,69]$. Other signs of neurological involvement include motor deficit as well as optic atrophy or damage in other cranial nerves [68].

This presentation is noticeable with hydrocephaly, meningeal reinforcement by imaging procedures due to arachnoiditis, infarcts secondary to vasculitis and particularly, tuberculomas, which are the chief finding in these subjects [64]. Tuberculomas are identified as multiple ring-shaped lesions of diverse sizes, usually found together with symptom atology of focal neurological damage without evidence of systemic disease [70]. However, their presence in frontal, temporal, and optochiasmatic regions of the brain, is associated with a bad prognosis [68]. It has been reported that nearly half of the tuberculomas are recognized during the treatment of patients [64]. This effect may be related with the tuberculosis-immune reconstitution inflammatory syndrome (IRIS) seen in HIVinfected individuals treated with the HAART scheme as soon as two weeks after starting HIV therapy [66]. In such patients, a great number of neutrophil infiltrates at the CNS are associated with inflammasome activation and the concomitant abundance of myeloperoxidase, cathepsin G, lipocalin-2, MMP-8 and MMP9, among other pro-inflammatory cytokines [66]. Magnetic resonance is the diagnosis test of election, mostly when it is not possible to work with biopsies [68]. Nevertheless, the clinician should be aware that several reports of tuberculomas mistakenly diagnosed as oncological diseases can be found and that the successful diagnosis of tuberculosis in the CNS remains a clinical challenge [70].

\section{Tuberculous lymphadenitis}

Tuberculous lymphadenitis is the most common extra pulmonary tuberculosis presentation [71] due to the immune cell migration following tuberculosis infection [72], particularly in pediatric population and in women between 30-40 years of age [73]. Several risk factors are related with this presentation, including a Southern Asian ethnicity, previous oropharyngeal expositions to the M. tuberculosis complex, hormonal influences, immune suppression, and effects related to the immunization with the BCG vaccine $[73,74]$. The patient typically shows a slowly progressive and painless swelling of a unilateral group of lymph nodes, mostly affecting the peripheral and cervical lymph nodes, which can grow up to $8-10 \mathrm{~cm}$ in diameter during a period of $1-2$ months $[72,73]$. Besides, since lymph nodes are the primary site for adaptive immunity generation, the pathological study of the affected lymph nodes usually demonstrates the presence of granulomas, more frequently found in subjects coinfected with HIV [75]. Besides, the concomitant presences of 
pulmonary tuberculosis, as well as of disseminated diseases and of systemic symptoms including fever, are more common in HIVpositive patients than in HIV-negative individuals [73].

Finally, it is also necessary to mention the pediatric tuberculosis presentation. It is estimated that close to $11 \%$ of all the affected patients are under 15 years of age [76], a number that can grow to $20 \%$ in regions with high incidence of tuberculosis [77]. The fast and imperceptible progression towards the tuberculous disease is a particular characteristic of the pediatric patient [78]. Just as in adults, the most common site of tuberculosis in children is the lung [51]. The most reported symptoms are chronic cough (longer than 4 weeks of duration), dyspnea, asthenia, thoracic pain, hemoptysis, deviation from the expected trajectory in the growth curve, and bad response to the initial treatment. All of them variate according to the age and the immunological state of the minor $[51,76]$. Infants and scholar children show highly variable presentations that can be clinically and radio logically similar to common respiratory infections; however, during adolescence the manifestations are the same as in adults [51]. Although normal chest radiographies in children are found-even with confirmed tuberculosis, the presence of pronounced hilaradenopathy and with or without compression of the airway, the diagnosis of pulmonary tuberculosis is suggested [76]. Less than $15 \%$ of the cases are positive for the identification of M. tuberculosis in sputum while growing the bacteria in culture has a rate of success around $30-50 \%$ [78]. Given the difficulty of obtaining sputum samples from children, it has been reported that the combination of chronic cough, weight loss and anorexia, is highly predictive of tuberculosis in patients under 15 years of age [51]. The habitual absence of sputum production with cough in children is related with a lower contagiousness [26].

\section{Diagnosis}

The detection of M. tuberculosis infection is still a challenge. Despite the most widely employed diagnostic techniques are the cutaneous tuberculin test and the IFN- $\gamma$ release test (described later in this section), the isolation of the bacilli is not possible when the infection has been eradicated by the immune system [79]. Furthermore, distinguishing between latent infection and active tuberculosis is still complicated using these diagnostic approaches [2]. Below we briefly describe the most commonly employed diagnostic tests for the diagnosis of M. tuberculosis infection.

\section{Detection and isolation of mycobacteria}

The detection by bacilloscopy and the bacteria culture are the definitive diagnosis of active tuberculosis and the primary examination methods for patients with tuberculosis symptoms [80]. The diagnosis is based on the identification of the bacilli in sputum. But, when the sputum cannot be obtained, it is induced or the sample is taken from nasopharyngeal aspiration [81]. The staining techniques employed are Ziehl-Neelsen for conventional microscopy and auramine-rhodamin for fluorescence microscopy [80].

In the particular case of the central nervous system, the identification of the bacteria by Ziehl-Neelsen has been complicated because of the required volume of cerebrospinal liquid. In consequence, a modified Ziehl-Neelsen stain based on centrifugation on slides using cerebrospinal liquid samples has been recently demonstrated to be more sensitive than the conventional stain for diagnosis in CNS and provides a diagnosis with $0.5 \mathrm{ml}$ samples [82]. The WHO guidelines establish that two-three slides per patient must be analyzed in successive days; the results should show evidence of the bacilli in more than two days for a definitive diagnosis of the infection [83]. However, the employment of direct microscopy as an option for rapid detection is difficult in the clinical practice because only $44 \%$ of new cases in adults and $15-20 \%$ in children have the bacilli in sputum samples [80]. Because of that, it is advisable to perform other diagnosis methods (including tuberculin test, IFN- $\gamma$ release test, PCR, and/or chest radiography) when there is suspicion of infection, even with a negative isolation result [80].

Cellular culture is the reference method to detect $M$. tuberculosis with the employment of Middle brook 7H11 and Lowenstein-Jensen media. Although cell culture is more sensitive than detecting the bacilli in sputum samples, these two media require more than two weeks to detect colonies in solid culture [11] (Figure 4). There currently exist multiple commercial culture systems that are based on a liquid medium, which require less time for the detection of bacterial growth [80].

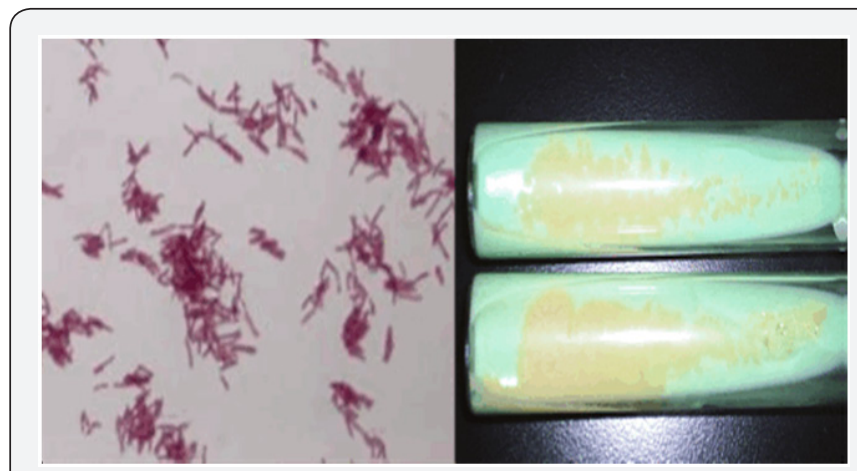

Figure 4: Phenotypic characteristics of Mycobacterium tuberculosis complex Ziehl-Neelsen stain demonstrating the Mycobacterium bacilli in red color (left picture)and cell culture of M. tuberculosis in Löwenstein-Jensen medium (right picture).

\section{Cutaneous tuberculin test (Mantoux test)}

Tuberculin detects delayed cutaneous hypersensitivity, useful for the differentiation of latent infection by M. tuberculosis [84]. The tuberculin reaction is measured as in duration in millimeters 48-72 hours after the sub dermal application of purified protein derivate (PPD) of the mycobacteria under the skin in the anterior side of the forearm $[80,85]$ (Table 1). Both sensitivity and specificity rely on the size of the in duration 
elected as cut-off value, the immune system of the patient, and unspecific reactions, which can be due to previous exposition to environmental mycobacteria or BCG vaccination [2]. Indeed, clinical reports support the presence of positive PPD tests in patients affected with cervical lymphadenitis due to non tuberculoses mycobacteria such as the complex M. aviumintracellular, M. haemophilum, M. simiae and M. scrofulaceum, in whom a PPD in duration of $>15 \mathrm{~mm}$ is commonly seen [86].

Table 1: Positive results in the tuberculin assay. The table shows the three possible positive results in the tuberculin assay by sub dermal application of PPD, according to the characteristics of each patient $[133,134]$.

\begin{tabular}{|c|c|}
\hline $\begin{array}{c}\text { Induration } \\
\text { size }\end{array}$ & Patients Positive for the Test \\
\hline$>5 \mathrm{~mm}$ & $\begin{array}{c}\text { Immunosuppressed patient with fibrotic changes } \\
\text { demonstrated by thoracic radiography, consistent with } \\
\text { previous tuberculous disease or in current contact } \\
\text { with infective tuberculous cases }\end{array}$ \\
\hline$>10 \mathrm{~mm}$ & $\begin{array}{c}\text { Subject that works or lives in high-risk areas; } \\
\text { intravenous drug consumer; patient with concomitant } \\
\text { diseases including silicosis, diabetes mellitus, chronic } \\
\text { kidney failure, leukemia, lymphoma; patient with } \\
\text { sudden and unexplainable weight loss } \geq 10 \% ; \text { subject } \\
\text { with gastrectomy or yeyunoileal bypass; patient } \\
\text { younger than 4 years of age }\end{array}$ \\
\hline$>15 \mathrm{~mm}$ & Any person, regardless the associated risk factors \\
\hline
\end{tabular}

Furthermore, the age of vaccination has been demonstrated as a critical determinant of the response to PPD test. One metaanalysis of 24 studies revealed that such vaccination during infancy is associated with 8.5 false-positive tuberculin tests per 100 vaccines, being 2.6 of these false positives reactions of $>15 \mathrm{~mm}$ [87]. Since this response could be a clinical problem in populations with high prevalence of non-tuberculous infection and low prevalence of tuberculosis infections, previous studies have focused on the description of common proteins among mycobacteria that can potentially act for further Cutaneous tests. They have shown that the L7/L12 proteins in the ribosomal 50 subunit, as well as the hypothetical proteins WAG31 and Rv3075c, are potential candidates of common proteins in mycobacteria [88].

\section{In-vitro IFN- $\gamma$ release test with Quantiferon-TB Gold kit}

This diagnostic method is based on the principle that T-lymphocytes release IFN- $\gamma$ when they re-encounter specific antigens belonging to M. tuberculosis. To perform the test, a fresh blood sample with a viable content of leucocytes is required. The sample is incubated with controls and a mixture of synthetic peptides representing the M. tuberculosis antigens ESAT-6, CFP10 and TB7-7 [80,89]. The IFN- $\gamma$ released is then identified in the supernatant after incubation with antigens. Alternatively, the IFN- $\gamma$-producer cells are counted in an enzyme-linked immune sorbent assay (ELISA) [2]. This test is useful to detect latent tuberculosis and is more specific than the tuberculin test because the antigens employed for the detection of IFN $-\gamma$ are unique in M. tuberculosis and are not associated with either BCG vaccine or any other non-tuberculosis mycobacteria, including M. avium [90].

\section{Polymerase chain reaction (PCR)}

This test is rapid, highly specific ( $>90 \%$ for pulmonary tuberculosis) and can predict antibiotic resistance. It is possible to amplify and detect rRNA or DNA from the mycobacteria with the employment of either blood, cerebrospinal fluid, sputum, bone marrow, or a tissue sample [80]. This is a useful and cheap test for the detection of the bacilli in a diverse range of samples. It provides bacteriological information with multiple weeks of anticipation compared with cellular culture [91].

\section{Radiography and computed tomography}

The radiological diagnosis of pulmonary tuberculosis is a challenge, mainly in immune suppressed patients that present atypical patterns [92]. Primary tuberculosis is manifested as four entities by radiography: parenchymal disease, lymphadenopathy, pleural effusion, and miliary disease, which can be combined in the same patient. Parenchymal damage is identified as a dense consolidation, predominantly in the superior pulmonary lobe due to the reduced lymphatic drainage and the reduced local oxygenation [93]. While, a multi-lobar disease can be identified in around 25\% of the cases [94] (Figure5). The appearance of parenchymal damage tends to be similar to that of bacterial pneumonia, but it can be differentiated by the presence of lymphadenopathy and the absence of response to conventional antibiotics [95].

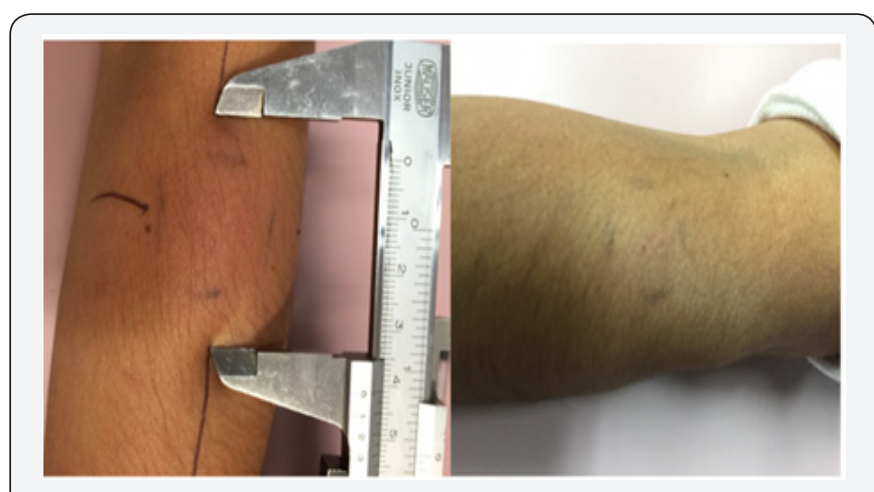

Figure 5: Tuberculin test Positive test showing in duration $>15 \mathrm{~mm}$ (left picture) and negative test without demonstrated in duration (right picture). In both cases, the subcutaneous application site is demarked with ink by the health worker. For the positive test, a straight line is drawn up to the point where it reaches in duration.

Nearly $66 \%$ of the cases are solved without sequels during the firsts two years; in the rest, the presence of acalcified parenchyma scar, known as Ghon nodule, is commonly the only evidence of previous tuberculosis [94,96] (Figure 6). Right unilateral lymphadenopathy, with both ipsilateral hilar and paratracheal involvement, is also commonly identified. The presence of calcified hilar nodules together with a Ghon lesionis known as the Ranke complex [95]. Miliary disease is more common among 


\section{International Journal of Pulmonary \& Respiratory Sciences}

children, elderly population, and immunosuppressed patients. At the beginning of the clinical presentation it is associated only with pulmonary hyperinflation [95]. However, as the disease progresses, diffused nodules of 2-3mm diameter are identified. They are predominantly distributed in the inferior lobules of the lungs, may coalesce and do not calcify [95] (Figure 7).
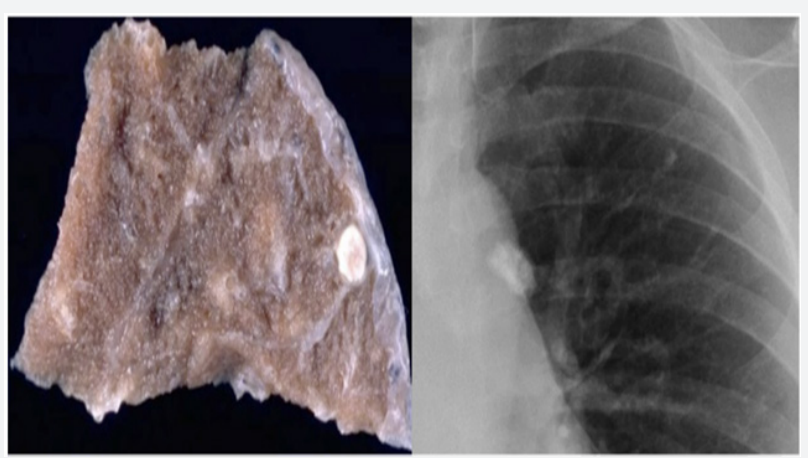

Figure 6: Histopathological sample of lung The image shows the Ghon lesion (left picture) and a thoracic radiography with presence of the Ranke complex (right picture).

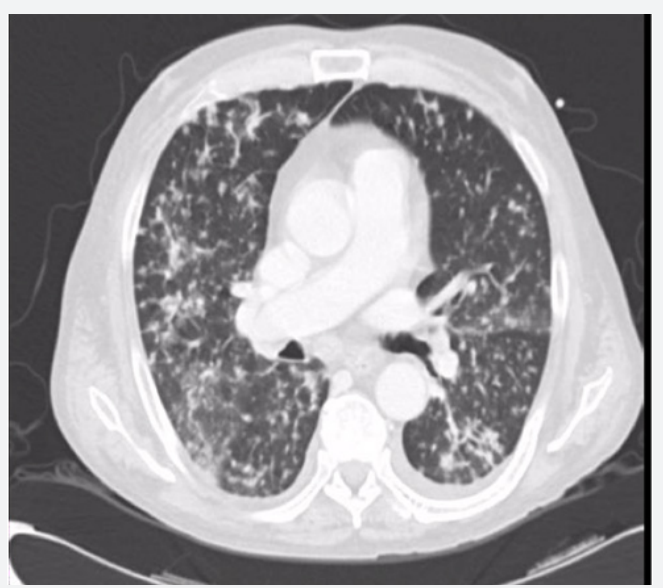

Figure 7: Computed tomography of miliary tuberculosis. Trans-versal slide showing bilateral and symmetric pulmonary hyperinflation with multiple nodules, predominantly in the right lung, adopting the characteristic miliary pattern throughout both lung fields.

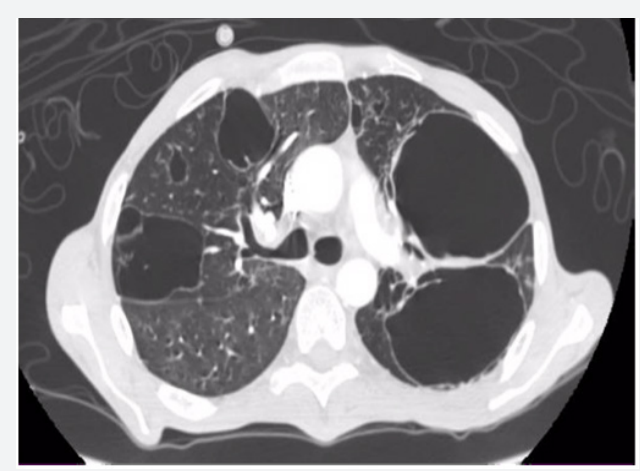

Figure 8: Computed tomography of tuberculous disease. Transversal slide showing diverse irregular non-confluent cavitations with predominance in peripheral areas of both lung fields.
On the other hand, secondary tuberculosis is identified focally or in patch heterogeneous consolidations found in apical and posterior segments of superior lobules and in superior segments of inferior lobules [94]. Cavitations, which indicate primary disease, can progress to endobronchial areas and form the typical "sprout tree" distribution, considered an active tuberculosis marker. The elected method that demonstrates an early bronchogenic spread is computed tomography [94] (Figure 8).

\section{Positron-emission tomography with computed tomography}

The position-emission tomography with 18-fluoro-2-deoxiD-glucose with computed tomography $\left({ }^{18} \mathrm{~F}\right.$-FDG PET-CT) is a non-invasive tool in which the pulmonary and extra pulmonary variants of tuberculosis are simultaneously evaluated [92] (Figure 9). It is not a habitual procedure for the diagnosis of tuberculosis since it is commonly performed in the search for cancer. Its employment is based on the detection of an increase in the glucose metabolism, which is related with the rise of macrophage and neutrophil activity in tuberculosis [92]. The glucose uptake rate is reported as the standardized uptake value (SUV), being maximal in active tuberculosis [96].

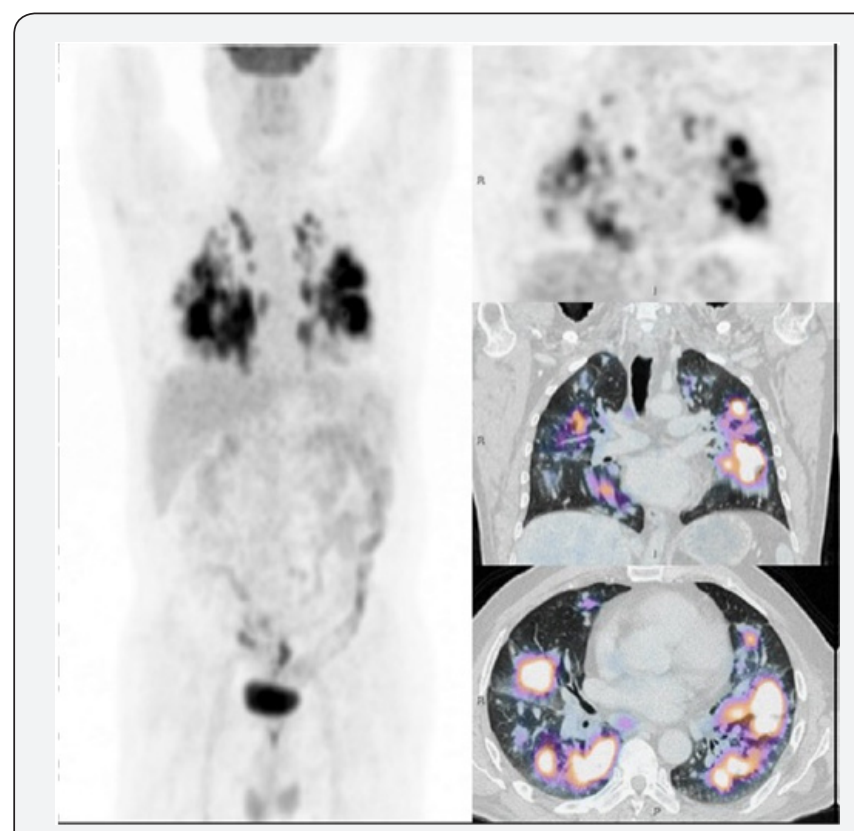

Figure 9: F-FDG PET-CT from a 69-year old masculine patient with cancer suspicion. Micro nodules, nodules and diffuse masses with a tendency to coalesce are seen in both lung fields. Larger nodules and masses are observed in parahilar zones in relation with the sites with the highest metabolic activity of the pulmonary parenchyma. Bilateral affection and involvement of segmental and sub segmental bronchi, without conditioning obstruction, and with diffuse and heterogeneous uptake. Presence of ganglia in paratracheal space as well as in aortopulmonary, infracarinal, and parahilar areas.

This technique is useful to evaluate the response to treatment when the radiological features are manifested with little or null changes [92]. There are two described patrons by ${ }^{18} \mathrm{~F}-\mathrm{FDG}$ PET- 
CT: one pulmonary, with consolidations in the superior lobule and cavitations or cavities surrounded by micro nodules and one lymphatic, which is represented by calcifications of the lymphatic nodules and requires the comparison of both the size and symmetry of them, which together, indicate the compromised nodules [97]. A clear correlation between the reductions in the accumulation of pulmonary ${ }^{18} \mathrm{~F}-\mathrm{FDG}$ and a successful antibiotic treatment has been demonstrated [98]. However, the main limitations of ${ }^{18} \mathrm{~F}-\mathrm{FDG}$ PET-CT are its expensiveness, low specificity, and lack in the capacity to discern a granulomatous disease with malignant involvement [92].

\section{Serological detection of antigens}

In the absence of other diagnostic methods, it is possible to employ the serum diagnostic to search for lipoarabinomannan (LAM) with ELISA. However, the anti-LAM antibodies do not distinguish between pathogenic and non-pathogenic mycobacteria strains and can generate crossed reactivity against other LAM-producer genus bacteria, such as Nocardia [99].

\section{Nucleic acid amplification with Genexpert}

The presence of $M$. tuberculosis can be detected using a real time PCR-based technique with both pulmonary and nonpulmonary samples. This technique can also simultaneously find resistance to rifampicin [100]. For this test, mutations (present in $95-98 \%$ of all the rifampicin-resistant strains) in the resistantdeterminant region of the $r p o B$ gene are detected with the employment of five specific molecular probes designed for this purpose [101]. This is a simple, sensible and specific approach [100]; it has proven its affectivity in isolated cases in New York, Madrid, India, and Mexico [102]. Furthermore, since most of the isolated mycobacteria that are resistant to rifampicin are also resistant to isoniazid, this method could be useful to identify multi-resistant strains [102]. Currently, the Cepheid Genexpert system processes human samples by real-time PCR to identify multi-resistant strains in less than two hours with a sensibility close to that of the M. tuberculosis cell culture [102]. Besides, since it requires a processing time of less than five minutes per human subject, the diagnostic human error rate is considerably reduced [101].

\section{DNA aptamer detection}

One of the newest techniques for tuberculosis diagnosis is the mycobacterial DNA aptamer detection. DNA aptamers, oligonucleotide chains that fold in specific structures to bind to several molecules, are analog to antibodies and possess high stability [99]. Aptamers are highly sensible and specific for the identification of almost any molecule. Since they can be produced by chemistry synthesis or by PCR, their cost is low, between 10 to 50 times less than the required to produce antibodies [103]. Nowadays there are DNA aptamers specific for the identification of the polyphosphate kinase 2 (PPK2) of M. tuberculosis [103]. Researchers have recently described a diagnostic method based on the generation of particular aptamers for the glycolipid antigen ManLAM of the Beijing strain of M. tuberculosis, which has shown similar detection rates as the obtained with diagnostic kits [99].

\section{Treatment and Prevention}

The Millennial Development Goals were eight objectives that the United Nations Organization wanted to achieve by the year of 2015; they included the fight against major diseases, as tuberculosis [104]. A big effort promoting an accessible treatment has been made, but the co-infection of $M$. tuberculosis with HIV and the existence of tuberculosis strains with different degrees of resistance to antibiotics have generated a complex control [105]. Therefore, members of the WHO are working on the Sustainable Development Goals (SDGs) to end with the global tuberculosis epidemic between 2015 and 2030. With the WHO End Tuberculosis Strategy and using a pharmacological approach, they aim to reduce the tuberculosis-associated deaths in $90 \%$ and the tuberculosis incidence rate in $80 \%$ by 2030, compared with 2015 [1]. In this section, we will address the current treatments for tuberculosis and prevention with vaccination.

\section{Treatment}

Although the successful treatment rates have been maintained since the year 2007, the emergence of M. tuberculosis strains with extended spectrum of antibiotics resistance has complicated the therapeutic approach to tuberculosis [104]. In fact, tuberculosis can be curable in $85 \%$ of cases if treated correctly [80]. Even though studies have demonstrated that by the second week of treatment the infectivity potential of the patient is diminished, it is highly recommended to complete the treatment scheme [2].

The first-line treatment is based on use of isoniazid, rifampicin, Pyrazinamide, and Ethambutol [106], with a standardized approach of both rifampicin and isoniazid for six months and Pyrazinamide and ethambutol during the firsts two months [77]. On the other hand, the second-line treatment includes cycloserine, terizidone, ethionamide, prothionamide, capreomycin, amino salicylic acid, amino glycosides such as kanamycin and amikacin, and fluoroquinolones including ofloxacin, levofloxacin, gatifloxacin and moxifloxacin [77]. Together with the specific treatment, the usage of adjuvant corticosteroids has been suggested to reduce the inflammation state of the patient [6].

The treatment scheme depends on the immune state of the patient and the resistance the bacterium shows; in consequence, the pharmacological therapy must be maintained up to 24 months in some cases [6] (Table 2). A particular case is that of patients with latent infection, for whom the recommended treatment is isoniazid during a period of 6-9 months in order to reduce the risk of tuberculosis disease, especially if they had contact with patients that demonstrate the active form [77]. 


\section{International Journal of Pulmonary \& Respiratory Sciences}

Table2: Approaches in the tuberculous patient. Recommended treatment schemes by the CDC guidelines for the different tuberculosis presentations.

\begin{tabular}{|c|c|c|c|}
\hline Tuberculosis Presentation & Recommended Treatment & Duration of the Treatment & Commentary \\
\hline \multirow[b]{4}{*}{ Latent tuberculosis } & INH & 7 doses/week (9 months) & \multirow{3}{*}{$\begin{array}{l}\text { For co-infected patients with HIV, children of } \\
\text { 2-11 years of age, and pregnant woman with } \\
\text { pyridoxine supplementation }\end{array}$} \\
\hline & INH & 7 doses/week (6 months) & \\
\hline & INH and RIF & 1 dose/week (3 months) & \\
\hline & RIF & 1 dose/week (4 months) & $\begin{array}{c}\text { For patients co-infected with HIV under } \\
\text { antiretroviral treatment, subjects older than } \\
12 \text { years of age, patients infected with } M \text {. } \\
\text { tuberculosis strains resistant to INH or RIF, and } \\
\text { pregnant woman or any woman intending to get } \\
\text { pregnant during treatment period }\end{array}$ \\
\hline \multirow{4}{*}{ Tuberculous disease } & \multirow[t]{2}{*}{$\begin{array}{l}\text { INH, RIF, PZA and EMB } \\
\text { (initial phase) + INH and } \\
\text { RIF (continuation phase) }\end{array}$} & $\begin{array}{c}7 \text { doses/week for } 56 \text { doses ( } 8 \\
\text { weeks) }\end{array}$ & $\begin{array}{l}\text { Preferred regime if the treatment with PZA } \\
\text { was not concluded during the initial phase, or } \\
\text { if any cavernous lesions with positive sputum } \\
\text { culture are present after the firsts two months } \\
\text { of treatment. Extend the continuation phase to } \\
\text { seven months }\end{array}$ \\
\hline & & $\begin{array}{c}7 \text { dose/week for } 126 \text { doses (18 } \\
\text { weeks) }\end{array}$ & $\begin{array}{c}\text { Alternative to preferred regime if direct } \\
\text { observation therapy is complicated }\end{array}$ \\
\hline & \multirow{2}{*}{$\begin{array}{l}\text { INH, RIF, PZA and EMB } \\
\text { (initial phase) + INH and } \\
\text { RIF (continuation phase) }\end{array}$} & $\begin{array}{c}7 \text { doses/week for } 56 \text { doses (8 } \\
\text { weeks) }\end{array}$ & \\
\hline & & $\begin{array}{c}3 \text { doses/week for } 54 \text { doses ( } 18 \\
\text { weeks) }\end{array}$ & \\
\hline \multirow[t]{2}{*}{$\begin{array}{l}\text { Extra-pulmonary } \\
\text { tuberculosis }\end{array}$} & \multirow[t]{2}{*}{$\begin{array}{l}\text { INH, RIF, PZA and EMB } \\
\text { (initial phase) + INH and } \\
\text { RIF (continuation phase) }\end{array}$} & $\begin{array}{c}7 \text { doses/week for } 56 \text { doses ( } 8 \\
\text { weeks) }\end{array}$ & $\begin{array}{l}\text { The same therapeutical principles as in } \\
\text { pulmonary tuberculosis are applied, unless } \\
\text { the bacillus is resistant to first-line treatment. } \\
\text { If it is not possible to employ PZA, treatment } \\
\text { is extended for } 7 \text { months. An optimal duration } \\
\text { for meningeal tuberculosis has not been } \\
\text { established, although experts recommend } 9-12 \\
\text { months. Corticosteroids are not recommended } \\
\text { as additional therapy in neither meningeal nor } \\
\text { pericarditis presentations Direct observation } \\
\text { therapy is always recommended }\end{array}$ \\
\hline & & $\begin{array}{c}7 \text { doses/week for } 126 \text { doses (18 } \\
\text { weeks) }\end{array}$ & \\
\hline \multirow{2}{*}{$\begin{array}{l}\text { Tuberculosis associated } \\
\text { with resistant strains }\end{array}$} & $\begin{array}{l}\text { INH, RIF, PZA and EMB } \\
\text { (first-line treatment) }\end{array}$ & 6-9 months & $\begin{array}{l}\text { Between } 4 \text { and } 6 \text { new drugs are recommended } \\
\text { for MDR strains resistant to other first-line } \\
\text { treatment besides INH and RIF and patients that } \\
\text { have demonstrated susceptibility by in vitro } \\
\text { assay. In MDR strains resistant only to PZA (first- } \\
\text { line drug), consider that the disease could be } \\
\text { caused by M. bovis instead of M. tuberculosis }\end{array}$ \\
\hline & $\begin{array}{l}\text { Aminoglycosides, } \\
\text { fluoroquinolones, } \\
\text { capreomycin, cycloserine, } \\
\text { aminosalicylic acid, } \\
\text { thioamides (second-line } \\
\text { treatment) }\end{array}$ & 2 years & $\begin{array}{l}\text { Consider that MDR strains resist INH and RIF, } \\
\text { and PZA and EMB, possibly. For XDR strains, the } \\
\text { treatment should be based on resistance in vitro } \\
\text { assays and epidemiological data }\end{array}$ \\
\hline
\end{tabular}

Abbreviations: INH: Isoniazid; RIF: Rifampicin; PZA: Pyrazinamide; EMB: Ethambutol [116,133,135].

Isoniazid is a prodrug that requires activation by the catalase peroxidase (KatG) to target the NADH-dependent enoyl ACP reductase InhA, which then stops the mycolic acid synthesis [107]. Rifampicin is a DNA-dependent RNA polymerase inhibitor that forms a stable complex with this enzyme to prevent the initiation of bacterial RNA synthesis [108]. Pyrazinamide is a prodrug activated by acidic $\mathrm{pH}$ and transformed by the bacterial pyrazinamidase into its active form, pyrazinoic acid, to affect the membrane transport in the bacteria [109]. Ethambutol is a drug that alters the structure of the mycobacterial cellular wall inhibiting the transference of arabinogalactan into the wall and $\left[\mathrm{D}-{ }^{14} \mathrm{C}\right]$-glucose into the $\mathrm{D}$-arabinose residue of the arabinogalactan molecule [110]. 
The preventive therapy with antibiotics or prophylaxis in countries with high prevalence of the infection should be limited to co-infected patients with HIV and children under 5 years of age that have contact with infected subjects at home. Contrastingly, in countries with low prevalence, the application of the preventive therapy is recommended in immigrants from countries with high prevalence and people that have a close contact with latently infected patients [6]. Furthermore, another group that must be considered for the preventive therapy is that of healthcare workers, in whom the conversion surveillance by PPD can indicate the necessity of prophylaxis. Indeed, due to their close contact with patients and/or with potentially infected material from patients, healthcare workers are in continuous risk of exposition and possible acquisition of the bacillus. In the United States, the CDC recommends to adequately follow the hospital infection control standards as a primary strategy of prevention amongst this group of workers, since other people inside the hospital, including patients and visitors, may not vaccinated against $M$. tuberculosis [111]. In countries with high prevalence of tuberculosis, both the surveillance and the control among healthcare workers should be attended with specific programs of prevention and control.

It must be considered that a preventive approach does not only directly affect the health of the population, mostly in underdeveloped countries, but also has a deep impact on the economy. In the case of tuberculosis, a standard therapy of 6 months costs around $\$ 2000$ dollars/patient in industrialized countries, a cost which can be expanded up to 25 times if the subject is infected with a multi-drug resistant strain (MDR) or with an extensively resistant strain (XDR) [112].

Although drug resistance in tuberculosis treatment was discovered in 1946 after the introduction of streptomycin $[113,114]$. MDR strains emerged around the world more than 25 years ago, with the subsequent development of XDR and recently, strains that resist both first and second line drugs, known as extremely multidrug resistant strains (XXDR) $[113,115]$. These groups of resistant mycobacteria are transmitted in the same way as $M$. tuberculosis strains that are susceptible to pharmacological treatment [26]. Tuberculosis by MDR is generated by $M$. tuberculosis strains that resist at least the two most effective drugs against tuberculosis, isoniazid and rifampicin, while XDR strains also resist any fluoroquinolone and one of the three injectable treatments (capreomycin, kanamycin or amikacin) [115]. These bacteria can acquire their resistance through any of two ways, known as primary and secondary resistances. The primary form occurs in patients initially exposed and infected by resistant organisms, and the secondary develops during the treatment of tuberculosis, either due to an inaccurate regime (the patient did not follow the prescribed scheme properly) or mal absorption of the drugs [116].

Even though the exact proportion of MDR and XDR strains is not known, in 2008 the WHO estimated that $3.6 \%$ of the incident cases in the world were caused by MDR; half of them were identifiable in India and China. This Organization also reported that MDR strains were responsible for approximately 150,000 deaths during the same year [115] since less than $1 \%$ of MDR bacilli cases were treated properly [77].

In countries such as Estonia, Lithuania, Azerbaijan and Ukraine, XDR strains are associated with more than $10 \%$ of all the MDR cases. In Eastern Europe and in the Sub-Saharan Africa the HIV/AIDS epidemic has promoted the prevalence of MDR strains [115]. On the other hand, we now know that more than $12 \%$ of the incident cases and more than $50 \%$ of the previously treated cases in countries that used to belong to the Union of Soviet Socialist Republics are MDR strains [115]. It has been reported that is the case of the city of Minsk, in Belarus, more than one third of the incident tuberculosis cases were caused by MDR bacteria [113], which reveals that the approach to MDR tuberculosis has been insufficient. This information, along with the fact that routine cellular cultures and drug susceptibility assays are done in only $22 \%$ of the countries around the world, worsens the prognosis for patients [115]. Furthermore, use of combined treatments of first and second line drugs to treatment of MDR and XDR strains is recommended, according to the results from the antibiotics susceptibility assay. Longer treatments are also suggested, even though it is known that the approach tends to be less effective and badly tolerated by the patient. Because of that, it is estimated that the percentage of patients with tuberculosis due to MDR strains heal in less than $69 \%$ of the cases, even after treatments lasting 18 months. According to experts, an ideal drug combination for a treatment includes at least three active drugs against MDR and XDR strains, which can have a complementary, synergic and potent effect against diverse subpopulations of M. tuberculosis [77].

Thanks to the employment of next generation sequencing technologies, the genome of $M$. tuberculosis has been demonstrated to be highly dynamic [117]. In fact, the main reason of resistance is a spontaneous genetic mutation in the bacteria, and not horizontal transference $[115,118]$. Nevertheless, this is a debatable statement since some reports have demonstrated a lack of association between treatment and the presence of mutations in the mycobacteria [119]; however, others show that recent mutations generating hetero resistance (presence of sensitive and resistant allele in the same sputum sample) are associated with induction of treatment [120]. In fact, it is known that in the presence of active tuberculosis, subpopulations of resistant mycobacteria emerge and can be the dominant strain under the pressure of the treatment [115]. Isoniazid resistance is related with mutations in its activator, $k a t G$, as well as with the gene mabA [121]. On the other hand, rifampicin resistance is almost always associated with a punctual mutation in the generpoB, which codifies for the $\beta$ subunit of RNA polymerase [12]. These mutations that confer resistance happen at predictable rates: for isoniazid, a resistance rate of $10^{-6}$ is expected; while a resistance close to $10^{-8}$ is expected for 
rifampicin [115]. Besides, a patient may present pulmonary tuberculosis by MDR strains that respond to treatment in different ways, depending on the anatomical localization of the pulmonary lesion [122].

Therefore, multiple efforts have been made in research to improve the treatment scheme for the benefit of the patient. There currently are at least ten different compounds in clinical development for tuberculosis approach, most of which are new drugs while others follow the strategy of therapeutic positioning [77].

\section{Vaccination}

The BCG vaccine consists in a live and attenuated strain of $M$. bovis, a species related to M. tuberculosis, derived from a virulent strain after 231 passages in potato and bills medium [85,123]; it is currently the only vaccine available against tuberculosis. This vaccine primarily protects against the most aggressive forms of the disease (miliary and meningeal) in children [15]. It has been employed since the early 1920s [124] when clinical studies done between 1921 and 1927 in France and Belgium demonstrated its high efficacy to protect against tuberculosis in children [85]. Initially it was administered orally, although by the 1930s the intradermic administration began in Scandinavian countries [85]. After the Second World War, the vaccine was given to all European children and the WHO extended its employment in endemic areas outside Europe by the beginning of the 1950s [85]. In 1974, the BCG vaccine was introduced in the extended immunization program of the WHO [125]. Nowadays, routine BCG vaccination in children is encouraged by the WHO and most of the countries around the world use it [126]. Today, more than 3 billion people have been inoculated with BCG, making it the most employed vaccine around the world [85].

The WHO currently recommends that all infants born in countries with a high risk of infection by $M$. tuberculosis must be vaccinated with an intradermic dose of BCG just after birth [85]. Despite its wide distribution, randomized controlled trials have revealed that BCG vaccine presents high clinical variability in the conferred protection against pulmonary tuberculosis, with an efficacy in the range of $0-80 \%$ and an average of 50\% [123]. Experts have proposed that this variation may be caused by nutritional and genetic characteristics of the population, as well as by previous exposition to non-tuberculous mycobacteria, differences in natural history of infection and disease, methodological variances between the trials, and even differences between the BCG formulations and in the time of their applications $[126,127]$. One systematic review of all the reported BCG trials until 2014 aimed to analyze the efficacy of $B C G$ vaccines using the univariate meta-regression method. The study revealed that the protective effect of BCG for pulmonary tuberculosis is greater if it is applied to subjects younger than school age and at latitudes farthest from the equator, with an absent or low protection in trials between latitudes $0^{\circ}-20^{\circ}$ and $20^{\circ}-40^{\circ}$, compared with those at $>40^{\circ}$ [5]. Presently, multiple laboratories have produced their own BCG strains. Among the BCG strains currently in use, there can be listed the Tokyo, Glaxo/Denmark, Moreau and Pasteur strains [123].

The BCG vaccine is accessible, stable, and secure; it is not affected by maternal antibodies and generates long-term immunity with only one dose [123]. The lowest rate of protection has been identified in countries with the highest incidence of tuberculosis, where results with the BCG vaccine have suggested a prevention success of deaths associated with tuberculosis close to $5 \%$ [85]. Therefore, there are two postulated strategies to improve the vaccination approach: to replace or to potentiate the BCG [128]. Replacing the BCG involves the employment of a more potent vaccine obtainable via genetic mutants of $M$. tuberculosis or the manipulation of the BCG vaccine to create recombinant strains ( $\mathrm{rBCG}$ ) that secrete antigens or other cytokines [128]. Work has been done in rBCGs that express the Ag85B antigen of $M$. tuberculosis, early secreted in the infection by this bacillus [129], to produce vaccines as the rBCG30 as well as strains that amplify the $\mathrm{T} \mathrm{CD}^{+}$response, expressing listeriolysin to perforate the phagosome membrane (rBCG $\Delta$ ureC:Hly) [128]. Additionally, researchers have generated rBCGs that promote a $\mathrm{Th}_{1}$ immune response via the production of cytokines including IFN- $\gamma$, IL-2, IL-2, and granulocyte and macrophage colony stimulating factor (GM-CSF) [123].

Regarding the second strategy, the design of vaccine boosts that increase the immune response generated by the vaccination in the childhood, as adjuvants, is postulated [128]. Studies have proposed several adjuvants including IC31, GLA-SE, AS01, and CAF01 as well as cationic liposomes that can promote a cellular immune response against M. tuberculosis [128,130-135].

\section{Conclusion}

Despite the efforts made by diverse organizations and several governments to reduce the incident cases of infection by $M$. tuberculosis, the disease remains a global public health problem. The diagnostic and therapeutic tools we currently have are insufficient for a correct approach in the patient. This limitation has stimulated the emergence of strains with diverse ranges of resistance to current treatments, a fact that worsens the prognosis of infected subjects. Furthermore, the rise in the number of patients affected by HIV/AIDS increases the risk of propagation of the bacillus and induces a shorter survival time of HIV/AIDS patients. Therefore, there must bea continuous research that allows us to identify new treatment schemes useful against resistant strains. The development of accessible, fast, sensitive, and specific diagnostic methods should also be promoted by clinical microbiology laboratories of the governments around the world. Their efforts should reveal the presence of Mycobacterium strains either sensitive or resistant to standard treatments in order to start a timely approach in the patient. Finally, we must promote the prevention of the acquisition of the bacillus by improving the BCG vaccine and its administration in highly vulnerable areas. Altogether, these 
efforts may promote a better prognosis for the population and should reduce the incident cases of tuberculosis infections.

\section{References}

1. World Health Organization (2016) Global Tuberculosis Report 2015 WHO.

2. Yates TA, Khan PY, Knight GM, Taylor JG, McHugh TD, et al. (2016) The transmission of Mycobacterium tuberculosis in high burden settings. Lancet Infect Dis 16(2): 227-238.

3. World Health Organization (2015) Tuberculosis. WHO.

4. Barry CE, Boshoff HI, Dartois V, Dick T, Ehrt S, et al. (2009) The spectrum of latent tuberculosis: rethinking the biology and intervention strategies. Nat Rev Microbiol 7(12): 845-855.

5. Mangtani P, Abubakar I, Ariti C, Beynon R, Pimpin L, et al. (2014) Protection by BCG vaccine against tuberculosis: a systematic review of randomized controlled trials. Clin Infect Dis 58(4): 470-480.

6. Dheda K, Barry CE, Maartens G (2015) Tuberculosis. Lancet 387(10024): 1211-1226.

7. Brites D, Gagneux S (2015) Co-evolution of Mycobacterium tuberculosis and Homo sapiens. Immunol Rev 264(1): 6-24.

8. Gagneux S (2012) Host-pathogen co-evolution in human tuberculosis. Philos Trans R Soc Lond B Biol Sci 367(1590): 850-859.

9. Daniel TM (2006) The history of tuberculosis. Respir Med 100(11) 1862-1870.

10. Cambau E, Drancourt M (2014) Steps towards the discovery of Mycobacterium tuberculosis by Robert Koch, 1882. Clin Microbiol Infect 20(3): 196-201.

11. Dias MF, Bernardes Filho F, Quaresma MV, Nascimento LV, Nery JA (2012) Update on cutaneous tuberculosis. An Bras Dermatol 89(6): 925-938.

12. Machado D, Couto I, PerdigaoJ, Rodrigues L, Portugal I, et al. (2012) Contribution of efflux to the emergence of isoniazid and multidrug resistance in Mycobacterium tuberculosis. PLoS One 7(4): e34538.

13. World Health Organization (2016) The End TB Strategy WHO.

14. Fox GJ, Orlova M, Schurr E (2016) Tuberculosis in Newborns: The Lessons of the "Lubeck Disaster" (1929-1933). PLoS Pathog 12(1): e1005271.

15. Flores-Moreno K, Celis-Meneses JS, Meneses-Ruiz DM, Castillo-Rodal AI, Orduna P, et al. (2014) Potential cross-reactivity of monoclonal antibodies against clinically relevant mycobacteria. Clin Exp Immunol 177(2): 454-463.

16. Zhu L, Zhong J, Jia X, Liu G, Kang Y, et al. (2016) Precision methylome characterization of Mycobacterium tuberculosis complex (MTBC) using PacBio single-molecule real-time (SMRT) technology. Nucleic Acids Res 44(2): 730-743.

17. Gengenbacher M, Kaufmann SH (2012) Mycobacterium tuberculosis: success through dormancy. FEMS Microbiol Rev 36(3): 514-532.

18. Smith I (2003) Mycobacterium tuberculosis pathogenesis and molecular determinants of virulence. Clin Microbiol Rev 16(3): 463496.

19. Sakamoto K (2012) The pathology of Mycobacterium tuberculosis infection. Vet Pathol 49(3): 423-439.

20. Cole ST, Brosch R, Parkhill J, Garnier T, Churcher C, et al. (1998) Deciphering the biology of Mycobacterium tuberculosis from the complete genome sequence. Nature 393(6685): 537-544.

21. Carel Nukdee K, Cantaloube S, Bonne M, Diagne CT, Laval F, et al. (2014) Mycobacterium tuberculosis proteins involved in mycolic acid synthesis and transport localize dynamically to the old growing pole and septum. PLoS One 9(5): e97148.

22. Smith T, Wolff KA, Nguyen L (2013) Molecular biology of drug resistance in Mycobacterium tuberculosis. Curr Top Microbiol Immunol 374: 5380.

23. Koch ML, Cote RA (1965) Comparison of Fluorescence Microscopy with Ziehl-Neelsen Stain for Demonstration of Acid-Fast Bacilli in Smear Preparations and Tissue Sections. Am Rev Respir Dis 91: 283284.

24. Sadaphal P, Rao J, Comstock GW, Beg MF (2008) Image processing techniques for identifying Mycobacterium tuberculosis in ZiehlNeelsen stains. Int J Tuberc Lung Dis 12(5): 579-582.

25. Turner RD, Bothamley GH (2015) Cough and the transmission of tuberculosis. J Infect Dis 211(9): 1367-1372.

26. Control, C.f.D (2013) Transmission and Pathogenesis of Tuberculosis. In: Core Curriculum on Tuberculosis: What the Clinician Should Know, V H National Center for HIV/AIDS, STD and TB Prevention, USA p. 1944.

27. Fennelly KP (2007) Variability of airborne transmission of Mycobacterium tuberculosis: implications for control of tuberculosis in the HIV era. Clin Infect Dis 44(10): 1358-1360.

28. Pai M, Kalantri S, Aggarwal AN, Menzies D, Blumberg HM (2006) Nosocomial tuberculosis in India. Emerg Infect Dis 12(9): 1311-1318.

29. Chandrashekara S, Anupama KR, Sambarey A, Chandra N (2016) High IL- 6 and low IL-15 levels mark the presence of TB infection: A preliminary study. Cytokine 81: 57-62.

30. Gallant JL, Viljoen AJ, van Helden PD, Wiid IJ (2016) Glutamate Dehydrogenase Is Required by Mycobacterium bovis BCG for Resistance to Cellular Stress. PLoS One 11(1): e0147706.

31. Cook GM, Hards K, Vilcheze C, Hartman T, Berney M (2014) Energetics of Respiration and Oxidative Phosphorylation in Mycobacteria. Microbiol Spectr 2(3): doi: 10.1128.

32.Zenteno-Cuevas R, Hernandez-Morales RJ, Perez-Navarro LM, MunizSalazar R, Santiago-Garcia J (2016) A rapid PCR assay to characterize the intact pks15/1 gene, a virulence marker in Mycobacterium tuberculosis. J Microbiol Methods 121: 33-35.

33. Shi L, Sohaskey CD, Kana BD, Dawes S, North RJ, et al. (2005) Changes in energy metabolism of Mycobacterium tuberculosis in mouse lung and under in-vitro conditions affecting aerobic respiration. Proc Natl Acad Sci U S A 102(43): 15629-15634.

34. Boshoff HI, Barry CE $3^{\text {rd }}(2005)$ Tuberculosis - metabolism and respiration in the absence of growth. Nat Rev Microbiol 3(1): 70-80.

35. Divangahi M, Chen M, Gan H, Desjardins D, Hickman TT et al. (2009) Mycobacterium tuberculosis evades macrophage defenses by inhibiting plasma membrane repair. Nat Immunol 10(8): 899-906.

36. Mihret A (2012) The role of dendritic cells in Mycobacterium tuberculosis infection. Virulence 3(7): 654-659.

37. Chen M, Divangahi M, Gan H, Shin DS, Hong S (2008). Lipid mediators in innate immunity against tuberculosis: opposing roles of PGE2 and LXA4 in the induction of macrophage death. J Exp Med 205(12): 27912801.

38. Duan L, Gan H, Golan DE, Remold HG (2002) Critical role of mitochondrial damage in determining outcome of macrophage infection with Mycobacterium tuberculosis. J Immunol 169(9): 51815187.

39. Divangahi M, Desjardins D, Nunes-Alves C, Remold HG, Behar SM (2010) Eicosanoid pathways regulate adaptive immunity to Mycobacterium tuberculosis. Nat Immunol 11(8): 751-758. 
40. Mendoza-Coronel E, Camacho-Sandoval R, Bonifaz LC, Lopez-Vidal Y (2011) PD-L2 induction on dendritic cells exposed to Mycobacterium avium down regulates BCG-specific $\mathrm{T}$ cell response. Tuberculosis (Edinb) 91(1): 36-46.

41. Saunders BM, Frank AA, Orme IM, Cooper AM (2000) Interleukin-6 induces early gamma interferon production in the infected lung but is not required for generation of specific immunity to Mycobacterium tuberculosis infection. Infect Immun 68(6): 3322-3326.

42. Martinez AN, Mehra S, Kaushal D (2013) Role of interleukin 6 in innate immunity to Mycobacterium tuberculosis infection. J Infect Dis 207(8): 1253-1261.

43. Moreira-Teixeira L, Sousa J, McNab FW, Torrado E, Cardoso F, et al. (2016) Type I IFN Inhibits Alternative Macrophage Activation during Mycobacterium tuberculosis Infection and Leads to Enhanced Protection in the Absence of IFN-gamma Signaling. J Immunol 197(12): 4714-4726.

44. Silva Miranda M, Breiman A, Allain S, Deknuydt F, Altare F (2012) The tuberculous granuloma: an unsuccessful host defence mechanism providing a safety shelter for the bacteria? Clin Dev Immunol 2012: 139127.

45. Guirado E, Schlesinger LS (2013) Modeling the Mycobacterium tuberculosis Granuloma - the Critical Battlefield in Host Immunity and Disease. Front Immunol 4: 98.

46. Ramakrishnan L (2012) Revisiting the role of the granuloma in tuberculosis. Nat Rev Immunol 12(5): 352-366.

47. Guirado E, Schlesinger LS (2013) Modeling the Mycobacterium tuberculosis Granuloma - the Critical Battlefield in Host Immunity and Disease. Front Immunol 4: 98.

48. Russell DG, Cardona PJ, Kim MJ, Allain S, Altare F (2009) Foamy macrophages and the progression of the human tuberculosis granuloma. Nat Immunol 10(9): 943-948.

49. Jeong YJ, Lee KS (2008) Pulmonary tuberculosis: up-to-date imaging and management. AJR Am J Roentgenol 191(3): 834-844.

50. Getahun H, Matteelli A, Chaisson RE, Raviglione M (2015) Latent Mycobacterium tuberculosis infection. N Engl J Med 373(12): 11791180.

51. Knechel NA (2009) Tuberculosis: pathophysiology, clinical features, and diagnosis. Crit Care Nurse 29(2): 34-43.

52. Campbell IA, Bah-Sow O (2006) Pulmonary tuberculosis: diagnosis and treatment. BMJ 332(7551): 1194-1197.

53. Zumla A, Raviglione M, Hafner R, von Reyn CF (2013) Tuberculosis. N Engl J Med 368(8): 745-755.

54. Prabu V, Agrawal S (2010) Systemic lupus erythematosus and tuberculosis: a review of complex interactions of complicated diseases. J Postgrad Med 56(3): 244-250.

55. Hou CL, Tsai YC, Chen LC, Huang JL (2008) Tuberculosis infection in patients with systemic lupus erythematosus: pulmonary and extrapulmonary infection compared. Clin Rheumatol 27(5): 557-563.

56. Matsumoto T, Tanaka T, Kawase I (2006) Infliximab for rheumatoid arthritis in a patient with tuberculosis. N Engl J Med 355(7): 740-741.

57. Dutta NK, Illei PB, Jain SK, Karakousis PC (2014) Characterization of a novel necrotic granuloma model of latent tuberculosis infection and reactivation in mice. Am J Pathol 1084(7): 2045-2055.

58. He D, Bai F, Zhang S, Jiang T, Shen J, et al. (2013) High incidence of tuberculosis infection in rheumatic diseases and impact for chemo prophylactic prevention of tuberculosis activation during biologics therapy. Clin Vaccine Immunol 20(6): 842-847.

59. Wolfe F, Michaud K, Anderson J, Urbansky K (2004) Tuberculosis infection in patients with rheumatoid arthritis and the effect of infliximab therapy. Arthritis Rheum 50(2): 372-379.

60. Keyser FD (2011) Choice of Biologic Therapy for Patients with Rheumatoid Arthritis: The Infection Perspective. Curr Rheumatol Rev $7(1): 77-87$

61. Sharma SK, Mohan A, Sharma A, Mitra DK (2005) Miliary tuberculosis: new insights into an old disease. Lancet Infect Dis 5(7): 415-430.

62. van Crevel R, Ottenhoff TH, van der Meer JW (2002) Innate immunity to Mycobacterium tuberculosis. Clin Microbiol Rev 15(2): 294-309.

63. Sharma SK, Mohan A, Sharma A (2012) Challenges in the diagnosis \& treatment of miliary tuberculosis. Indian J Med Res 135(5): 703-730.

64. Cardenas G, Soto-Hernandez JL (2011) The many faces of central nervous system tuberculosis. Arch Neurol 68(8): 1078.

65. Rock RB, Olin M, Baker CA, Molitor TW, Peterson PK (2008) Central nervous system tuberculosis: pathogenesis and clinical aspects. Clin Microbiol Rev 21(2): 243-261.

66. Marais S, Lai RP, Wilkinson KA, Meintjes G, O'Garra A, et al. (2016) Inflammasome activation underlies central nervous system deterioration in HIV-associated tuberculosis. J Infect Dis pii: jiw561.

67. Majeed S, Singh P, Sharma N, Sharma S (2016) Title: role of matrix metalloproteinase -9 in progression of tuberculous meningitis: a pilot study in patients at different stages of the disease. BMC Infect Dis 16: 722 .

68. Brancusi F, Farrar J, Heemskerk D (2012) Tuberculous meningitis in adults: a review of a decade of developments focusing on prognostic factors for outcome. Future Microbiol 7(9): 1101-1116.

69. Torok ME (2015) Tuberculous meningitis: advances in diagnosis and treatment. Br Med Bull 113(10) 117-131.

70. Monteiro R, Carneiro JC, Costa C, Duarte R (2013) Cerebral tuberculomas - A clinical challenge. Respir Med Case Rep 9: 34-37.

71. Jawahar MS, Rajaram K, Sivasubramanian S, Paramasivan CN, Chandrasekar K, et al. (2005) Treatment of lymph node tuberculosis-a randomized clinical trial of two 6-month regimens. Trop Med Int Health 10(11): 1090-1098.

72. Maji A, Misra R, Kumar Mondal A, Kumar D, Bajaj D, et al. (2015) Expression profiling of lymph nodes in tuberculosis patients reveal inflammatory milieu at site of infection. Scientific Reports 5: 15214.

73. Fontanilla JM, Barnes A, von Reyn CF (2011) Current diagnosis and management of peripheral tuberculous lymphadenitis. Clin Infect Dis 53(6): 555-562.

74. Khandkar C, Harrington Z, Jelfs PJ, Sintchenko V, Dobler CC (2015) Epidemiology of Peripheral Lymph Node Tuberculosis and Genotyping of M. tuberculosis Strains: A Case-Control Study. PLoS One 10(7): e0132400.

75. Diedrich CR, O'Hern J, Gutierrez MG, Allie N, Papier P, et al. (2016) Relationship Between HIV Coinfection, Interleukin 10 Production, and Mycobacterium tuberculosis in Human Lymph Node Granulomas. Infect Dis 214(9): 1309-1318.

76. Perez-Velez CM, Marais BJ (2012) Tuberculosis in children. N Engl J Med 367: 348-361.

77. Ma Z, Lienhardt C, McIlleron H, Nunn AJ, Wang X (2010) Global tuberculosis drug development pipeline: the need and the reality. Lancet 375(9731): 2100-2109.

78. Swaminathan S, Rekha B (2010) Pediatric tuberculosis: global overview and challenges. Clin Infect Dis 50(Suppl 3): S184-194.

79. Verrall AJ, Netea MG, Alisjahbana B, Hill PC, van Crevel R (2014) Early clearance of Mycobacterium tuberculosis: a new frontier in prevention. Immunology 141(4): 506-513. 
80. Cheon SA, Cho HH, Kim J, Lee J, Kim HJ, (2016) Recent tuberculosis diagnosis toward the end TB strategy. J Microbiol Methods 123: 51-61.

81. Abbadi S, El Hadidy G, Gomaa N, Cooksey R (2009) Strain differentiation of Mycobacterium tuberculosis complex isolated from sputum of pulmonary tuberculosis patients. Int J Infect Dis 13(2): 236-242.

82. Chen P, Shi M, Feng GD, Liu JY, Wang BJ, et al. (2012) A highly efficient ziehl-neelsen stain: identifying de novo intracellular Mycobacterium tuberculosis and improving detection of extracellular $M$. tuberculosis in cerebrospinal fluid. J Clin Microbiol 50(4): 1166-1170.

83. World Health Organization WHO (2016) Systematic screening for active tuberculosis: principles and recommendations. WHO Swizerland.

84. Ahmad S (2011) Pathogenesis, immunology, and diagnosis of latent Mycobacterium tuberculosis infection. Clinical Development Immunology 814943

85. Andersen P, Doherty TM (2005) The success and failure of BCG implications for a novel tuberculosis vaccine. Nat Rev Microbiol 3(8): 656-662.

86. Haimi-Cohen Y, Zeharia A, Mimouni M, Soukhman M, Amir J (2001) Skin indurations in response to tuberculin testing in patients with nontuberculous mycobacterial lymphadenitis. Clin Infect Dis 33(10): 1786-1788.

87. Farhat M, Greenaway C, Pai M, Menzies D (2006) False-positive tuberculin skin tests: what is the absolute effect of BCG and nontuberculous mycobacteria? Int J Tuberc Lung Dis 10(11): 1192-1204.

88. Orduna P, Castillo-Rodal AI, Mercado ME, Ponce de Leon S, Lopez-Vidal Y (2015) Specific Proteins in Nontuberculous Mycobacteria: New Potential Tools. Biomed Res Int 2015: 964178.

89. Connell TG, Curtis N, Ranganathan SC, Buttery JP (2006) Performance of a whole blood interferon gamma assay for detecting latent infection with Mycobacterium tuberculosis in children. Thorax 61(7): 616-620.

90. Pai M, Denkinger CM, Kik SV, Rangaka MX, Zwerling A, et al. (2014) Gamma interferon release assays for detection of Mycobacterium tuberculosis infection. Clin Microbiol Rev 27(1): 3-20.

91. Kocagoz T, Yilmaz E, Ozkara S, Kocagoz S, Hayran M, et al. (1993) Detection of Mycobacterium tuberculosis in sputum samples by polymerase chain reaction using a simplified procedure. J Clin Microbiol 31(6): 1435-1438.

92. Vorster M, Sathekge MM, Bomanji J (2014) Advances in imaging of tuberculosis: the role of (1)(8)F-FDG PET and PET/CT. Curr Opin Pulm Med 20(3): 287-293.

93. Nemec SF, Bankier AA, Eisenberg RL (2013) Upper lobe-predominant diseases of the lung. AJR Am J Roentgenol 200(3): W222-237.

94. Skoura E, Zumla A, Bomanji J (2015) Imaging in tuberculosis. Int J Infect Dis 32: 87-93.

95. Burrill J, Williams CJ, Bain G, Conder G, Hine AL, et al. (2007) Tuberculosis: a radiologic review. Radiographics 27(5): 1255-1273.

96. Heysell SK, Thomas TA, Sifri CD, Rehm PK, Houpt ER (2013) 18-Fluorodeoxyglucose positron emission tomography for tuberculosis diagnosis and management: a case series. BMC Pulm Med 13: 14.

97. Soussan M, Brillet PY, Mekinian A, Khafagy A, Nicolas P, et al. (2012) Patterns of pulmonary tuberculosis on FDG-PET/CT. Eur J Radiol 81(10): 2872-2876

98. Sathekge M, Buscombe JR (2011) Can positron emission tomography work in the African tuberculosis epidemic? Nucl Med Commun 32(4) 241-244.

99. Tang XL, Wu SM, Xie Y, Song N, Guan Q, et al. (2016) Generation and application of ssDNA aptamers against glycolipid antigen ManLAM of Mycobacterium tuberculosis for TB diagnosis. J Infect 72(5): 573-586.
100. Zeka AN, Tasbakan S, Cavusoglu C (2011) Evaluation of the GeneXpert MTB/RIF assay for rapid diagnosis of tuberculosis and detection of rifampin resistance in pulmonary and extrapulmonary specimens. J Clin Microbiol 49(12): 4138-4141.

101. Marlowe EM, Novak-Weekley SM, Cumpio J, Sharp SE, Momeny MA, et al. (2011) Evaluation of the Cepheid Xpert MTB/RIF assay for direct detection of Mycobacterium tuberculosis complex in respiratory specimens. J Clin Microbiol 49(4): 1621-1623.

102. Helb D, Jones M, Story E, Boehme C, Wallace E, et al. (2010) Rapid detection of Mycobacterium tuberculosis and rifampin resistance by use of on-demand, near-patient technology. J Clin Microbiol 48(1): 229-237.

103. Rotherham LS, Maserumule C, Dheda K, Theron J, Khati M (2012) Selection and application of ssDNA aptamers to detect active TB from sputum samples. PLoS One 7(10): e46862.

104. World Health Organization (2015) Millennium Development Goals (MDGs). Fact sheet $\mathrm{N}^{\circ} 290$.

105. Raviglione MC, Uplekar MW (2006) WHO's new Stop TB Strategy. Lancet 367(9514): 952-955.

106. Wotld Health Organization (2010) Treatment of tuberculosis guidelines.

107. Tseng ST, Tai CH, Li CR, Lin CF, Shi ZY (2015) The mutations of katG and inhA genes of isoniazid-resistant Mycobacterium tuberculosis isolates in Taiwan. J Microbiol Immunol Infect 48(3): 249-255.

108. Campbell EA, Korzheva N, Mustaev A, Murakami K, Nair S, et al. (2001) Structural mechanism for rifampicin inhibition of bacterial rna polymerase. Cell 104(6):901-912.

109. Zhang Y, Wade MM, Scorpio A, Zhang H, Sun Z, et al. (2003) Mode of action of pyrazinamide: disruption of Mycobacterium tuberculosis membrane transport and energetics by pyrazinoic acid. J Antimicrob Chemother 52(5): 790-795.

110. Sreevatsan S, Stockbauer KE, Pan X, Kreiswirth BN, Moghazeh SL, et al.(1997) Ethambutol resistance in Mycobacterium tuberculosis: critical role of embB mutations. Antimicrob Agents Chemother 41(8): 1677-1681.

111. Control CF D (1997) Immunization of Health-Care Workers: Recommendations of the Advisory Committee on Immunization Practices (ACIP) and the Hospital Infection Control Practices Advisory Committee (HICPAC). MMWR Recomm Rep 46(RR-18): $1-42$.

112. Manjelievskaia J, Erck D, Piracha S, Schrager L (2016) Drug-resistant TB: deadly, costly and in need of a vaccine. Trans R Soc Trop Med Hyg 110(3): 186-191.

113. Migliori GB, Sotgiu G, Gandhi NR, Falzon D, DeRiemer K, et al. (2013) Drug resistance beyond extensively drug-resistant tuberculosis: individual patient data meta-analysis. Eur Respir J 42(1): 169-179.

114. Zumla A, Nahid P, Cole ST (2013) Advances in the development of new tuberculosis drugs and treatment regimens. Nat Rev Drug Discov 12(5): 388-404.

115. Gandhi NR, Nunn P, Dheda K, Schaaf HS, Zignol M, et al. (2010) Multidrug-resistant and extensively drug-resistant tuberculosis: a threat to global control of tuberculosis. Lancet 375(9728): 18301843.

116. Control (2013) Core Curriculum on Tuberculosis: What the Clinician Should Know. In VH National Center for HIV/AIDS STD and TB Prevention ed, pp. 139-187.

117. Sampson SL (2016) Strength in Diversity: Hidden Genetic Depths of Mycobacterium tuberculosis. Trends Microbiol 24(2): 82-84. 
118. Gillespie SH (2002) Evolution of drug resistance in Mycobacterium tuberculosis: clinical and molecular perspective. Antimicrob Agents Chemother 46(2): 267-274

119. O'Neill MB, Mortimer TD, Pepperell CS (2015) Diversity of Mycobacterium tuberculosis across Evolutionary Scales. PLoS Pathog 11: e1005257.

120. Sun G, Luo T, Yang C, Dong X, Li J, et al. (2012) Dynamic population changes in Mycobacterium tuberculosis during acquisition and fixation of drug resistance in patients. J Infect Dis 206(11): 1724 1733.

121. Tang J, Yam WC, Hen Z (2016) Mycobacterium tuberculosis infection and vaccine development. Tuberculosis (Edinb) 98: 30-41.

122. Liu Q Via LE, Luo T, Liang L, Liu X, et al. (2015) Within patient microevolution of Mycobacterium tuberculosis correlates with heterogeneous responses to treatment. Sci Rep 5(1): 17507.

123. Singh VK, Srivastava R, Srivastava BS (2016) Manipulation of BCG vaccine: a double-edged sword. Eur J Clin Microbiol Infect Dis 35(4): 535-543.

124. Luca S, Mihaescu T (2013) History of BCG Vaccine. Maedica (Buchar) 8(1): 53-58.

125. Husain AA, Daginawala HF, Singh L, Kashyap RS (2016) Current perspective in tuberculosis vaccine development for high TB endemic regions. Tuberculosis (Edinb) 98: 149-158.

126. Fine PE (1988) BCG vaccination against tuberculosis and leprosy. Br Med Bull 44(3): 691-703.

127. Brandt L, Feino Cunha J, Weinreich Olsen A, Chilima B, Hirsch P, et al. (2002) Failure of the Mycobacterium bovis BCG vaccine: some species of environmental mycobacteria block multiplication of BCG and induction of protective immunity to tuberculosis. Infect Immun 70(2): 672-678.

128. Andersen P (2007) Tuberculosis vaccines - an update. Nat Rev Microbiol 5(7): 484-487.

129. Tse MT (2011) Vaccines: Early and late protection from TB. Nat Rev Drug Discov 10(3): 176

130. Liu X, Da Z, Wang Y, Niu H, Li R, et al. (2016) A novel liposome adjuvant DPC mediates Mycobacterium tuberculosis subunit vaccine well to induce cell-mediated immunity and high protective efficacy in mice. Vaccine 34(11): 1370-1378.

131. Agger EM (2016) Novel adjuvant formulations for delivery of antituberculosis vaccine candidates. Adv Drug Deliv Rev 102: 73-82.

132. Brennan PJ, Crick DC (2007) The cell-wall core of Mycobacterium tuberculosis in the context of drug discovery. Curr Top Med Chem $7(5): 475-488$

133. Jensen PA, Lambert LA, Iademarco MF, Ridzon R, Cdc (2005) Guidelines for preventing the transmission of Mycobacterium tuberculosis in health-care settings, 2005. MMWR Recomm Rep 54(RR17): 1-141.

134. Control C.f.D (2011) TB Elimination Tuberculin Skin Testing In. (National Center fo HIV/AIDS, Viral Hepatitis, STD, and TB Prevention.

135. Nahid P, Dorman SE, Alipanah N, Barry PM, Brozek JL, et al. (2016) Official American Thoracic Society/Centers for Disease Control and Prevention/Infectious Diseases Society of America Clinical Practice Guidelines: Treatment of Drug-Susceptible Tuberculosis. Clin Infect Dis 63(7): e147-195.

\section{Your next submission with Juniper Publishers} will reach you the below assets

- Quality Editorial service

- Swift Peer Review

- Reprints availability

- E-prints Service

- Manuscript Podcast for convenient understanding

- Global attainment for your research

- Manuscript accessibility in different formats

( Pdf, E-pub, Full Text, Audio)

- Unceasing customer service

Track the below URL for one-step submission https://juniperpublishers.com/online-submission.php 